\title{
Crystallization of graft copolymers 1 . Graft chains miscible with main chains
}

\author{
Hiroki Takeshita ${ }^{1}$, Gen'ichiro Sasagawa $^{1}$, Katsuhiko Takenaka ${ }^{1,2}$, Masamitsu Miya $^{1}$ and Tomoo Shiomi ${ }^{1,2}$ \\ Crystallization of graft chains was investigated using poly(methyl methacrylate)-graft-poly(ethylene glycol), in which \\ poly(ethylene glycol) (PEG) is miscible with poly(methyl methacrylate) (PMMA). Various compositions of PEG (98, 83, 76 wt\%) \\ were used in poly(methyl methacrylate)-graft-poly(ethylene glycol) (GR98, GR83, GR76, respectively). More spherulites, that is, \\ nucleations, were generated for GR98 than for the corresponding PEG/PMMA homopolymer blend having a corresponding blend \\ composition. However, the growth rate $G$ of spherulites was remarkably low for all graft copolymers. In the relationship between \\ the value of $G$ and the PEG composition, the extrapolation to pure PEG did not yield the $G$ value for pure PEG. The apparent \\ activation energy of crystallization was high for graft copolymers, which was attributed to a high large surface free energy due \\ to the restriction of PEG chains by grafting. The rate of overall crystallization for GR98 was not very different from that for \\ PEG/PMMA blends. The Avrami index for graft copolymers was similar to that for blends and for the PEG homopolymer. Both \\ melting temperatures and degrees of crystallinity in the graft copolymers were depressed. In the blends of the graft copolymer \\ with the PEG homopolymer, the $G$ value of spherulites was governed by the $G$ value of the PEG homopolymer.
} Polymer Journal (2010) 42, 482-488; doi:10.1038/pj.2010.24; published online 7 April 2010

Keywords: crystallization; graft chain; poly(methyl methacrylate)-graft-poly(ethylene glycol)

\section{INTRODUCTION}

The crystallization behavior of multicomponent polymer systems such as polymer blends and block copolymers has been investigated extensively. ${ }^{1-12}$ In immiscible polymer blends and block copolymers, competition or combination between crystallization and phase separation affects both crystallization and the resulting structure. ${ }^{5-7}$ Especially in the crystallization of block copolymers from microphase-separated melts, the restriction of crystallization by microdomains is also important. ${ }^{7-10}$ By contrast, for miscible polymer blends, the kinetics of crystallization is affected by diluent effects and by the composition-dependent glass transition temperature (see Mandelkern, ${ }^{2}$ Chapter 11). 2,4,11,12

On the other hand, crystallization in graft copolymers has not been investigated as systematically (see Mandelkern, ${ }^{1}$ Chapter 5$) .{ }^{13}$ Crystallization of graft chains may depend on graft densities. ${ }^{13}$ If the main chains and graft chains are immiscible with each other, the effect of microphase separation may also have an important role, similar to block copolymers. Therefore, the effects of both grafting and microphase separation on the crystallization behavior of graft copolymers should be investigated more thoroughly.

In this series of reports, we present the crystallization behavior of graft copolymers. First, we reveal the crystallization of the graft chain itself before describing the results of our investigation on the effect of microphase separation. In this paper, we focus on the crystallization of graft chains, using poly(methyl methacrylate)-graft-poly(ethylene glycol). Because poly(methyl methacrylate) (PMMA) and poly (ethylene glycol) (PEG) are miscible with each other for PMMA/ PEG homopolymer blends, ${ }^{14,15}$ crystallization of graft PEG chains is not affected by microphase separation (For graft copolymers, our unpublished data suggest that PMMA main chains and PEG graft chains are miscible with each other. PMMA-graft-PEG with $50 \mathrm{wt} \%$ or $2.0 \mathrm{~mol} \%$ of PEG $\left(M_{\mathrm{n}}=5000\right)$ was quenched rapidly to $-30^{\circ} \mathrm{C}$ from the melt and crystallized isothermally at that temperature. No peak was observed in the differential scanning calorimetry thermogram during isothermal crystallization; in the subsequent heating process at $10{ }^{\circ} \mathrm{C} \mathrm{min}^{-1}$, a broad exothermal peak appeared in the range of -14 to $38^{\circ} \mathrm{C}$. This onset temperature of crystallization $\left(-14^{\circ} \mathrm{C}\right)$ is close to the $T_{\mathrm{g}}$ value of $-16^{\circ} \mathrm{C}$ obtained from the Fox equation, with $T_{\mathrm{g}}=-80^{\circ} \mathrm{C}$ for PEG and $110^{\circ} \mathrm{C}$ for PMMA. These results suggest that the graft copolymer is in a glassy state at $-30^{\circ} \mathrm{C}$. Therefore, we conclude that PMMA and PEG in the graft copolymer are miscible with each other in the melt.). Therefore, features of the crystallization of graft chains are elucidated by comparing with those in the corresponding polymer blends of PMMA/PEG.

\section{EXPERIMENTAL PROCEDURE}

Material

A series of poly(methyl methacrylate)-graft-poly(ethylene glycols) were prepared by free-radical polymerization of methacrylate-type PEG-macromono-

${ }^{1}$ Department of Materials Science and Technology, Nagaoka University of Technology, Nagaoka, Niigata, Japan and ${ }^{2}$ Center for Green-Tech Development in Asia, Nagaoka University of Technology, Nagaoka, Niigata, Japan

Correspondence: Professor T Shiomi, Department of Materials Science and Technology, Nagaoka University of Technology, 1603-1 Kamitomioka, Nagaoka, Niigata 940-2188, Japan.

E-mail: shiomi@vos.nagaokaut.ac.jp

Received 21 December 2009; revised 15 February 2010; accepted 18 February 2010; published online 7 April 2010 
mer (PEG-MA) and copolymerization of PEG-MA and methyl methacrylate (MMA).

The PEG monomethyl ether $\left(M_{\mathrm{n}}=5000\right)$, which was purchased from SigmaAldrich (St Louis, MO, USA), was purified through an alumina column (diameter: $2.6 \mathrm{~cm}$, length: $100 \mathrm{~cm}$ ) to remove any PEG with hydroxy groups on both chain ends. The resultant PEG was reacted with sodium naphthalene to form sodium alcoholates (PEG-Na). The PEG-MA was prepared by reaction of PEG-Na with methacryloyl chloride in tetrahydrofuran for $12 \mathrm{~h}$ at $25^{\circ} \mathrm{C}$. After desalting, PEG-MA was purified by reprecipitation with methanol/ petroleum ether (2/8), followed by freeze drying from a benzene solution. The product was characterized by ${ }^{1} \mathrm{H}$ NMR (JNM-GX400, JEOL Ltd., Tokyo, Japan) and size exclusion chromatography, and its functionality was determined to be $90 \%$.

Free-radical polymerization of PEG-MA and copolymerization of PEG-MA with MMA were performed in a degassed $20 \mathrm{wt} \%$ benzene solution for $72 \mathrm{~h}$ and 60 or $40 \mathrm{~h}$, respectively, at $60^{\circ} \mathrm{C}$ using $1 \mathrm{wt} \%$ AIBN as an initiator. The resulting polymers were fractionated with an acetone/n-hexane system to remove unreacted PEG-MAs and then freeze-dried from a benzene solution. Molecular weights were measured by size exclusion chromatography relative to a polystyrene standard, and PEG compositions were determined by ${ }^{1} \mathrm{H}$ NMR. Polymer characteristics are shown in Table 1; the methacryloyl group was excluded in the calculation of the PEG composition expressed in wt $\%$ for the graft copolymers. The blends of PEG and PMMA homopolymers are also shown in Table 1. The molecular weight of PMMA, which was purchased from Scientific Polymer Products Inc. (Ontario, NY, USA), was 30 000; the PEG was identical to that used for the MA synthesis. Blend samples were prepared by precipitation in petroleum ether from a $5 \mathrm{wt} \%$ chloroform solution, followed by freeze-drying from a benzene solution.

\section{Measurements}

Differential scanning calorimetry measurements were taken with $10 \mathrm{mg}$ for the PEG homopolymer and blends and with $20 \mathrm{mg}$ for graft copolymers using a SEIKO I\&E DSC20 apparatus (SEIKO I\&E Ltd., Tokyo, Japan). For isothermal crystallization, the sample was annealed for $15 \mathrm{~min}$ at $85^{\circ} \mathrm{C}$ and then rapidly cooled to a desired crystallization temperature $T_{\mathrm{c}}$. Isothermal crystallization was analyzed by time resolution of the exothermal peak. Melting behavior was observed by heating the sample from $T_{\mathrm{c}}$ at $10^{\circ} \mathrm{C} \mathrm{min}^{-1}$ after isothermal crystallization. Spherulites were observed by polarized optical microscopy under crossed polarizers with a $530 \mathrm{~nm}$ retardation plate using an OLYMPUS BH-2 instrument (Olympus Corporation, Tokyo, Japan) equipped with an OLYMPUS PM-10AK camera and a laboratory-made hot stage controlled by a LABOX-115-8-03T regulator (RKC Instrument Inc., Tokyo, Japan).

\section{RESULTS AND DISCUSSION}

Crystallization of graft copolymers and homopolymer blends

The degree of crystallinity and the equilibrium melting temperature, $T_{\mathrm{m}}{ }^{\mathrm{o}}$, for the samples crystallized isothermally in the indicated range of

Table 1 Characteristics of graft copolymers (GR) and blends with PMMA $^{\mathrm{a}}$ (BL)

\begin{tabular}{lcccc}
\hline & & & \multicolumn{2}{c}{ Comp.of $P E G^{\mathrm{c}}$} \\
\cline { 3 - 5 } Sample & $M_{n} \times 10^{-4}$ PEG & $M_{n} \times 10^{-4}$ copolymer $^{\mathrm{b}}$ & $(\mathrm{mol} \%)^{\mathrm{d}}$ & $(w t . \%)^{\mathrm{e}}$ \\
\hline PEG & 0.50 & - & - & 100 \\
GR98 & 0.50 & 3.3 & 100.0 & 98.0 \\
GR83 & 0.50 & 3.7 & 10.6 & 82.7 \\
GR76 & 0.50 & 3.1 & 6.7 & 75.8 \\
BL95 & 0.50 & - & - & 95.0 \\
BL83 & 0.50 & - & - & 82.7 \\
BL76 & 0.50 & - & - & 75.8 \\
\hline
\end{tabular}

a $\mathrm{Mw}$ of blended poly(methyl methacrylate) (PMMA) homopolymer is 30000 .

bDetermined by size exclusion chromatography relative to polystyrene.

cDetermined by ${ }^{1} \mathrm{H}$ NMR for graft copolymers.

${ }^{d}$ Composition of poly(ethylene glycol) (PEG) macromonomer.

efraction of PEG part in which the methacryloyl group is excluded for graft copolymers.
$T_{\mathrm{c}}$ are summarized in Table 2. Although the degree of crystallinity of PEG in the blends is not significantly decreased, the degree of crystallinity values of graft copolymers are considerably lower than those of the PEG homopolymer. These differences may have resulted from the connection of the PEG chain end and main chain preventing crystallization.

Equilibrium melting temperatures $T_{\mathrm{m}}{ }^{\mathrm{o}}$ were evaluated from Hoffmann-Weeks plots shown in Figure 1. The $T_{\mathrm{m}}{ }^{\mathrm{o}}$ obtained here for the graft chain with $M_{\mathrm{n}}=5000$ may be an apparent value, because the grafting effect may be diminished with an increasing molecular weight of the graft chains. As shown in Table 2, the $T_{\mathrm{m}}{ }^{\mathrm{o}}$ values in blends are lower than that of the PEG homopolymer because of the melting depression effect. The $T_{\mathrm{m}}{ }^{\mathrm{o}}$ values for the graft copolymers are even lower, which may have been caused by the grafting effect, as the junctions between the graft and main chains are excluded from crystallization. Such a melting depression has been investigated theoretically and experimentally in randomly crosslinked crystalline networks (see Mandelkern, ${ }^{1}$ Chapter 7), revealing the randomness of

Table 2 Equilibrium melting temperature $\left(T_{\mathrm{m}}{ }^{\circ}\right)$, degree of crystallinity (DC) and Avrami index ( $n$ ) obtained in the range of the indicated crystallization temperature $T_{\mathrm{c}}$

\begin{tabular}{lcccc}
\hline Sample & $T_{c}\left({ }^{\circ} \mathrm{C}\right)$ & $T_{m}{ }^{0}\left({ }^{\circ} \mathrm{C}\right)$ & $D C(\%)^{a}$ & $\mathrm{n}$ \\
\hline PEG & $34.5-46.3$ & 63.3 & $90-95$ & $2.1-2.3$ \\
GR98 & $30.3-40.5$ & 60.5 & $60-62$ & $2.3-2.7$ \\
GR83 & $24.0-32.0$ & 55.8 & $71-73$ & $2.0-2.5$ \\
GR76 & $16.2-24.0$ & 51.7 & $64-65$ & $2.4-2.6$ \\
BL95 & $32.5-36.3$ & 61.7 & $89-90$ & $2.1-2.4$ \\
BL83 & $34.0-42.1$ & 61.1 & $84-87$ & $2.3-2.6$ \\
BL76 & $32.1-40.2$ & 60.1 & $75-82$ & $2.7-3.0$ \\
\hline
\end{tabular}

aEstimated using $=8.79 \mathrm{~kJ} \mathrm{~mol}^{-1}$, normalized to PEG.

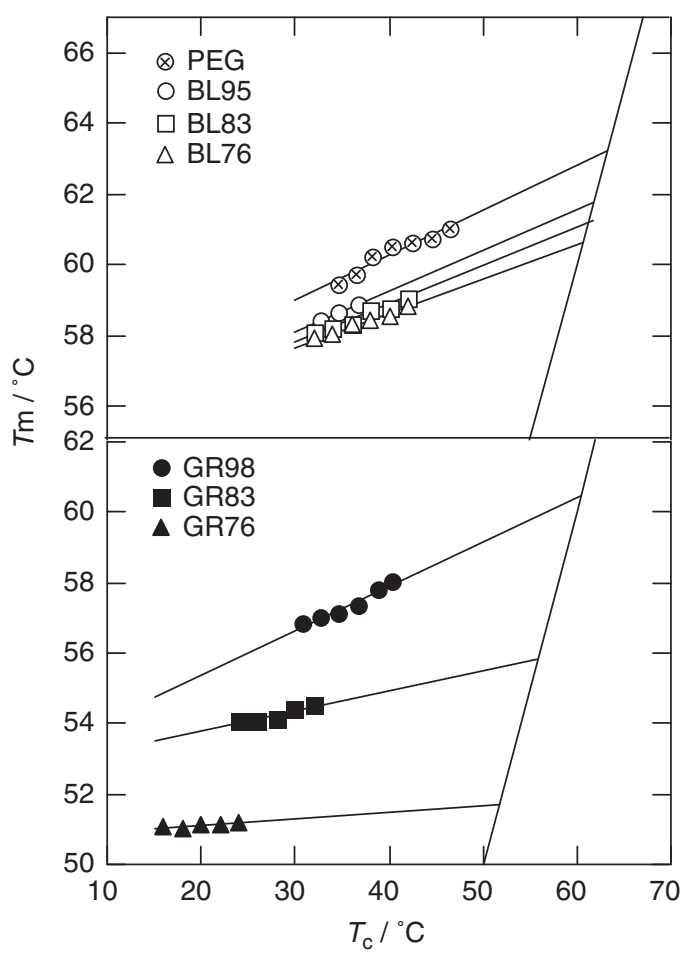

Figure 1 Hoffmann-Weeks plots for graft copolymers, PMMA/PEG blends and the PEG homopolymer. 
crosslinking, as well as the exclusion of junctions as contributing factors to lower $T_{\mathrm{m}}{ }^{0}$ values. Risch et al. ${ }^{13}$ observed $T_{\mathrm{m}}{ }^{0}$ values for three-arm and six-arm nylon- 6 polymers that were 5 and $8{ }^{\circ} \mathrm{C}$ lower than that for the linear one, respectively. They attributed this depression to greater fold surface energies due to local defects. The melting depression in the graft copolymers studied herein may also be caused by high fold surface free energies due to restriction of the chain end by its connection to the amorphous main chain in addition to exclusion of junctions. In fact, the $T_{\mathrm{m}}{ }^{\mathrm{o}}$ values of GR83 and GR76 are considerably lower.

Figure 2 displays the characteristics of the generation and development of spherulites for graft copolymers and blends. The number of generating spherulites, that is, nucleations, is larger for GR98 than BL95, even though their crystallization temperatures, $T_{\mathrm{c}}$ values, are

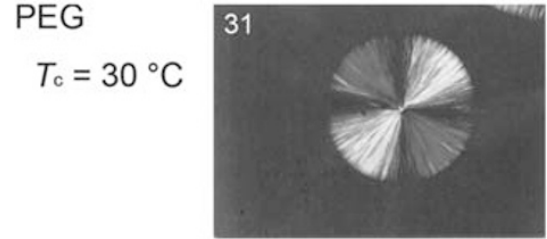

GR98
$T_{\mathrm{c}}=30^{\circ} \mathrm{C}$

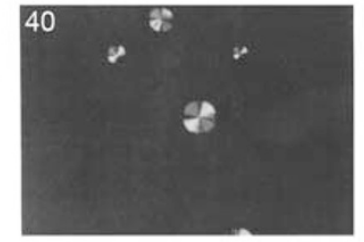

GR83

$T_{\mathrm{c}}=30^{\circ} \mathrm{C}$

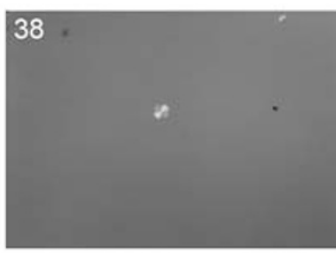

\section{GR76}

$T_{\mathrm{c}}=30^{\circ} \mathrm{C}$

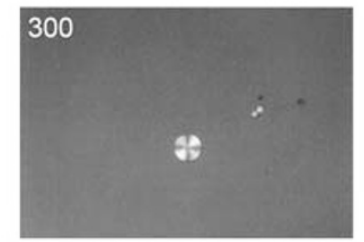

BL95
$T_{\mathrm{c}}=34{ }^{\circ} \mathrm{C}$

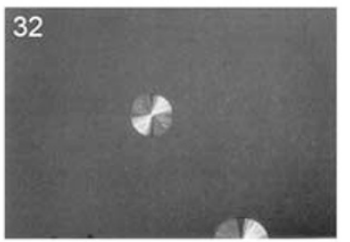

BL83

$T_{\mathrm{c}}=32^{\circ} \mathrm{C}$
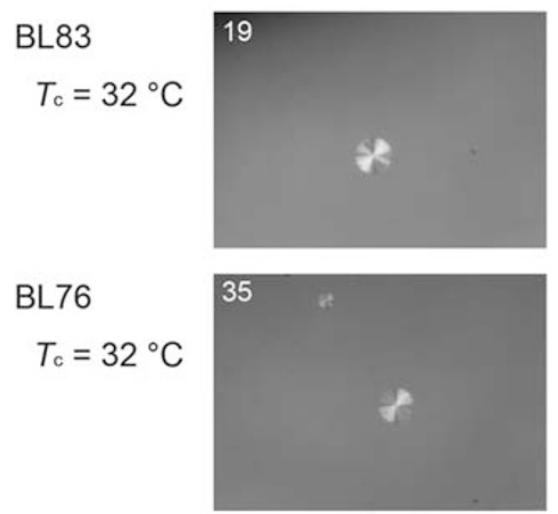
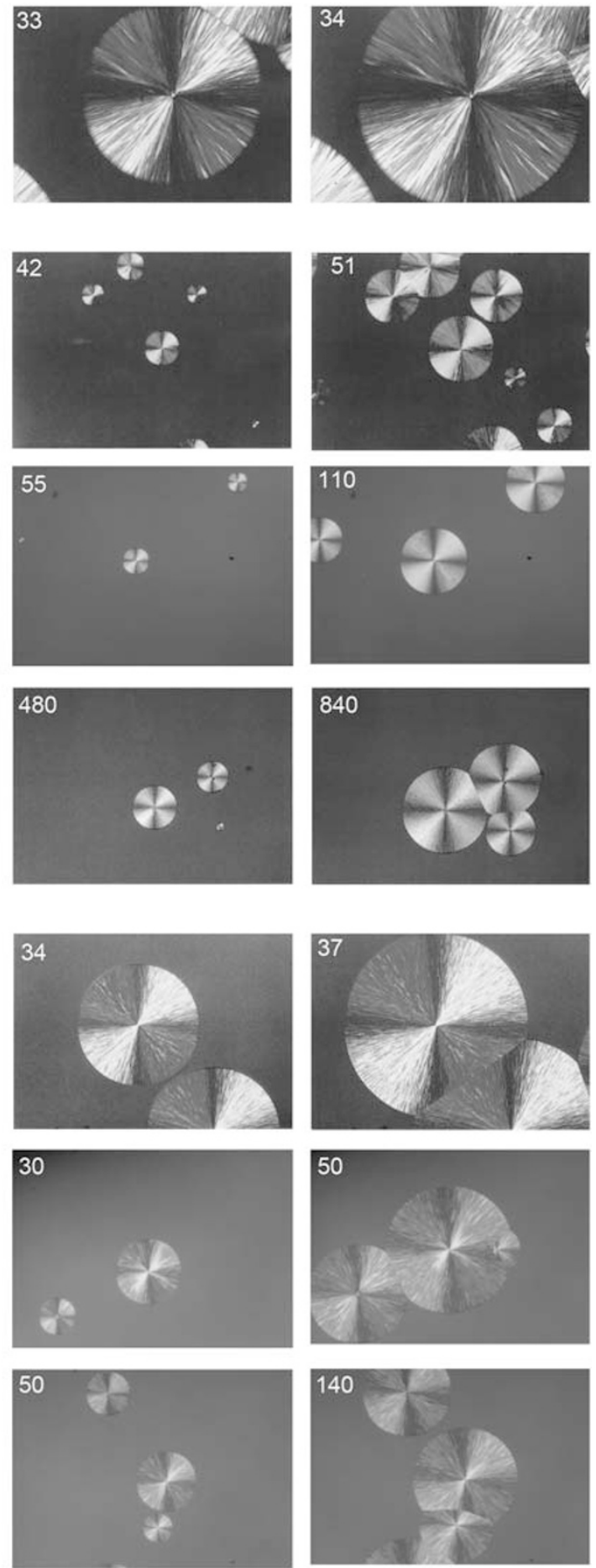

$500 \mu \mathrm{m}$

Figure 2 Development of spherulites for graft copolymers, PMMA/PEG blends and the PEG homopolymer. Numbers indicate the crystallization time and are expressed in seconds. 


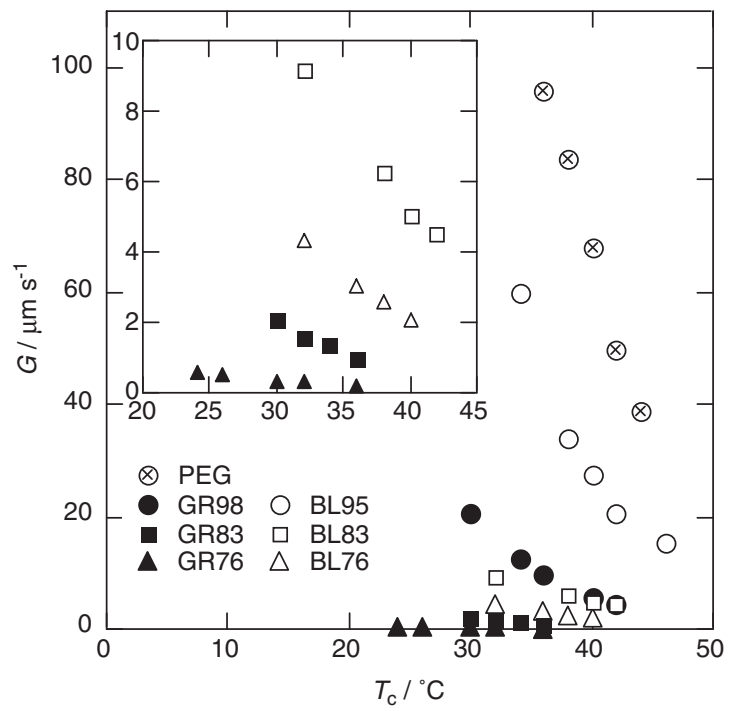

Figure 3 Growth rates of spherulites for graft copolymers, PMMA/PEG blends and the PEG homopolymer.

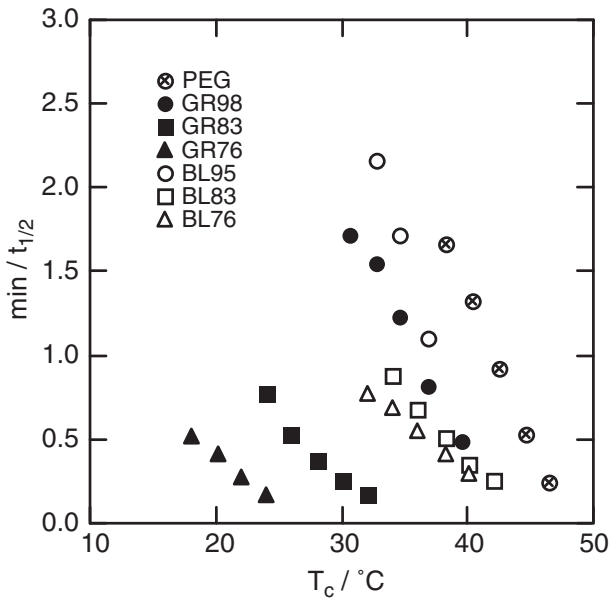

Figure 4 Reciprocals of the half-crystallization time for graft copolymers, PMMA/PEG blends and the PEG homopolymer.

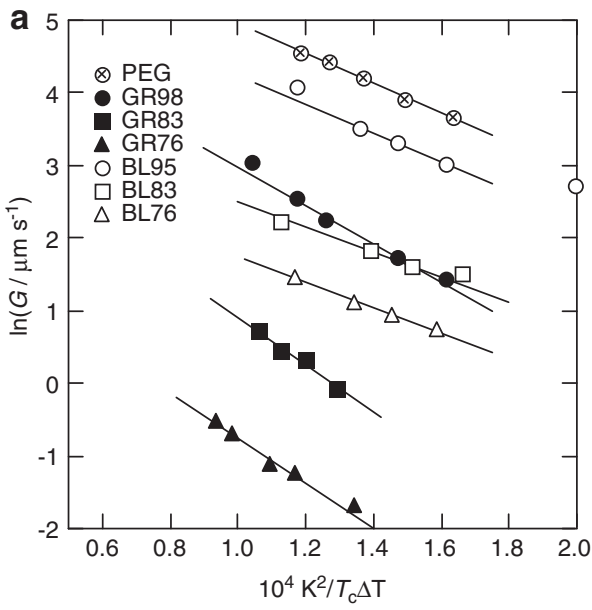

Figure 5 Dependence of the logarithm of the crystallization rate on $1 /\left(T_{\mathrm{c}} \Delta T\right)$ : (a) growth rates of spherulites and (b) overall crystallization rates.

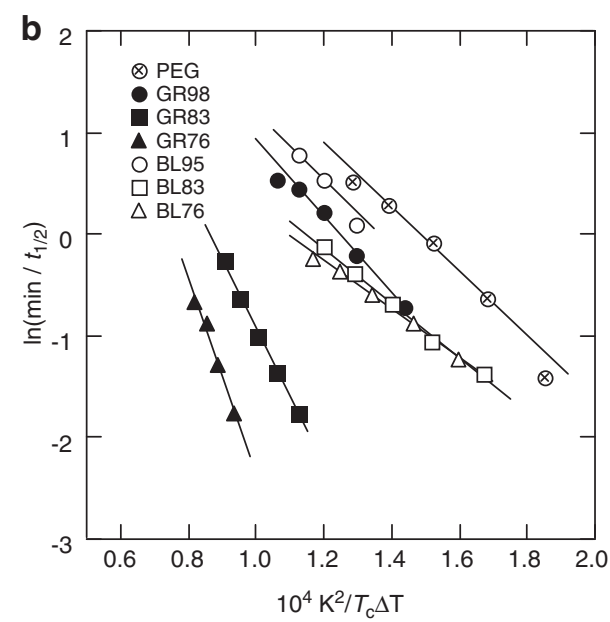

somewhat different. By contrast, as shown in Figure 3, the spherulite growth rate, $G$, is remarkably low for all graft copolymers, compared with those for the corresponding blends. The high nucleation rate in GR98 can be attributed to the high graft density. The decreased growth rate in graft copolymers may be due to low mobility or diminished diffusion rates of the graft chain.

Figure 4 shows the reciprocal $1 / t_{1 / 2}$ of the half-crystallization time, which was defined as the time taken for half of the crystallinity to develop; the $t_{1 / 2}$ value was determined from the differential scanning calorimetry exothermal peak. The value of $1 / t_{1 / 2}$ corresponds to the rate of overall crystallization and contains both nucleation and growth rates. As shown in Figure 4, the $1 / t_{1 / 2}$ value of GR98 is close to the value of its corresponding blend. These results are likely to be because the growth rate for GR98 is low, but its nucleation rate is high. By contrast, the $1 / t_{1 / 2}$ values of GR83 and GR76 are considerably lower than the corresponding BL83 and BL76, respectively, because growth rates and graft densities are low in these graft copolymers.

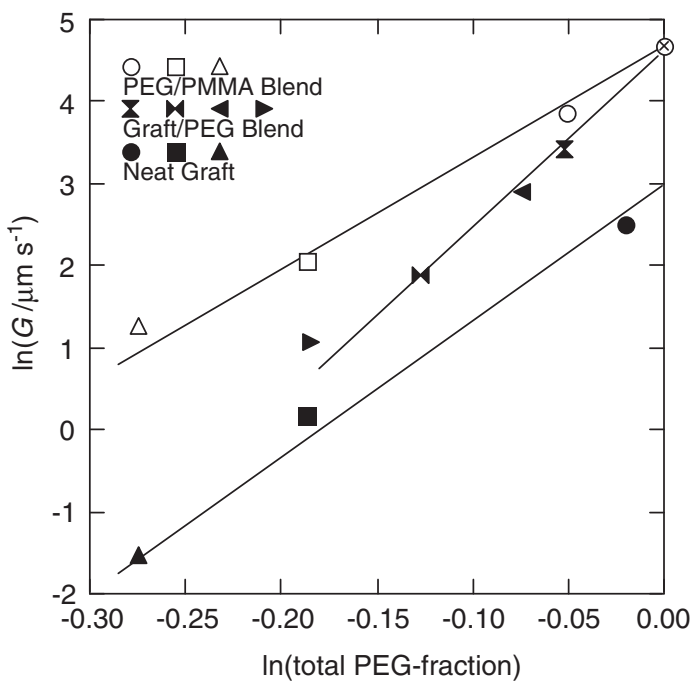

Figure 6 Dependence of spherulite growth rate on the total PEG fraction at $1 / \Delta T=3.5 \times 10^{-2} \mathrm{~K}^{-1}$. The symbols for PMMA/PEG homopolymer blends and neat graft copolymers are the same as those indicated in Figure 5, and those for blends with graft copolymers are the same as in Figure 8. 
Crystallization rates were analyzed on the basis of the TurnbullFischer equation. ${ }^{16}$ By extension to dilute systems, the crystallization rate $G$ can be written as

$$
G=\phi_{2} G_{0} \exp \left(-\Delta E / R T_{\mathrm{c}}\right) \exp \left(-\Delta \Phi / R T_{\mathrm{c}}\right)
$$

where $\phi_{2}$ is the volume fraction of the crystallizable component, $G_{0}$ is a constant and $\Delta E$ is the activation energy of transport. In addition, $\Delta \Phi$ is the free energy for nucleation, which can be expressed as ${ }^{17}$

$$
\Delta \Phi=k_{\mathrm{i}} b_{0} \sigma_{\mathrm{e}} \sigma_{\mathrm{s}} T_{\mathrm{m}}^{\mathrm{o}} / \Delta H_{\mathrm{f}} \Delta T-2 \sigma_{\mathrm{e}} R T_{\mathrm{c}} \operatorname{In} \phi_{2} /\left(b_{0} \Delta T\right),
$$

where $k_{\mathrm{i}}$ is the constant depending on Regime, $b_{0}$ is the distance between two adjacent fold planes, $\sigma_{\mathrm{s}}$ and $\sigma_{\mathrm{e}}$ are the lateral and end surface energies, respectively, $\Delta H_{\mathrm{f}}$ is the enthalpy of fusion per unit volume and $\Delta T$ is the degree of supercooling.

Figure 5 shows the plots of $\ln G$ and $\ln \left(1 / t_{1 / 2}\right)$ against $1 /\left(T_{\mathrm{c}} \Delta T\right)$. Here, $\Delta T$ for graft copolymers was taken on the basis of the $T_{\mathrm{m}}{ }^{\mathrm{o}}$ values of blends with the corresponding composition. The slopes of the plots of $\ln G$ for the blends (Figure 5a) are almost the same for BL95, BL83 and BL76 and are close to that for the PEG homopolymer. On the other hand, the slopes for graft copolymers are also identical for the three graft copolymers, but their slope is steeper than that for the blends and the homopolymer. The slope of the plots corresponds to the apparent activation energy of crystallization, which is the surface free energy. Therefore, the surface free energy in the spherulite growth is higher for the graft copolymer than for the blend and homopolymer, whereas that for the blend is similar to that of the homopolymer. These results coincide with the above discussion on melting temperatures. Transport energy may have affected the plots as well, especially for the graft copolymer, because of the restricted movement of the graft chains.

As shown in Figure 5b, although the slope of $\ln \left(1 / t_{1 / 2}\right)$ is considerably steeper for GR83 and GR76, the slope of GR98 is not significantly different from that of the blends and homopolymer. Accounting for the nucleation behavior described above for GR98, the total apparent
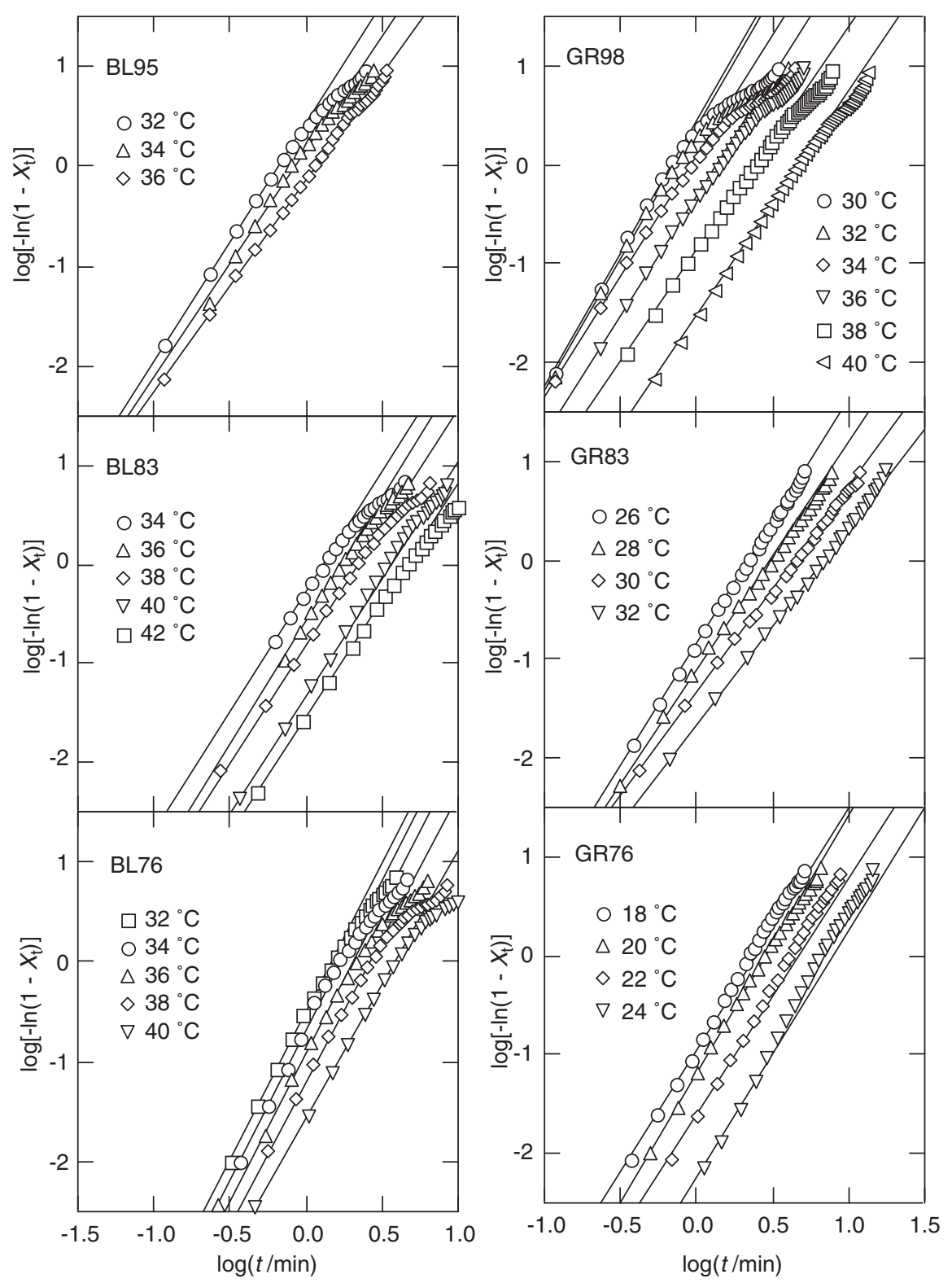

Figure 7 Avrami plots for graft copolymers and PMMA/PEG homopolymer blends. 
activation energy of nucleation and growth for GR98 is not so high, compared with that for the blends and homopolymer.

At a constant $\Delta T$, Equation (1) with (2) can be expressed as a function of $\ln \phi_{2}$ :

$$
\operatorname{In} G=A+B \operatorname{In} \phi_{2}
$$

when $T_{\mathrm{c}}$ is assumed to be the same at a constant $\Delta T$. Figure 6 shows the plots of $\ln G$ vs $\ln \phi_{2}$ for a series of graft copolymers and blends at $1 / \Delta T=3.5 \times 10^{-2} \mathrm{~K}^{-1}$. Both the graft copolymers and blends have a linear relationship to $\ln \phi_{2}$ as expressed by Equation (3). In blends, extrapolation to $\ln \phi_{2}=0$ gives the value of $\ln G$ for the PEG homopolymer; the results for blends reproduce Equation (3) for the diluted system. By contrast, in graft copolymers, extrapolation to $\ln \phi_{2}=0$ does not yield the value of $\ln G$ for the PEG homopolymer. Therefore, the crystallization kinetics in the diluted system cannot be simply applied to graft copolymers.

Figure 7 shows Avrami plots based on the following equation:

$$
\log \left[-\operatorname{In}\left(1-X_{\mathrm{t}}\right)\right]=\log K+n \log t,
$$

which is derived from the Avrami equation

$$
X_{\mathrm{t}}=1-\exp \left(-K t^{n}\right),
$$

where $X_{\mathrm{t}}$ is the fraction of crystallinity at crystallization time $t, K$ is the overall crystallization rate constant and $n$ is the Avrami index, which depends on the type of nucleation and the dimension of the crystal growth. Index $n$ can be estimated from the initial slope of the Avrami plots. The values of $n$ obtained from the plots shown in Figure 7 are listed in Table 2. The values of $n$ are almost the same (2-3) for all of the samples, suggesting that the type of nucleation in the graft copolymer is the same as that in the homopolymer.

\section{CRYSTALLIZATION OF BLENDS OF GRAFT COPOLYMER WITH PEG HOMOPOLYMER}

Figure 8 shows the growth rate of spherulites for blends of the graft copolymer with the PEG homopolymer at various crystallization

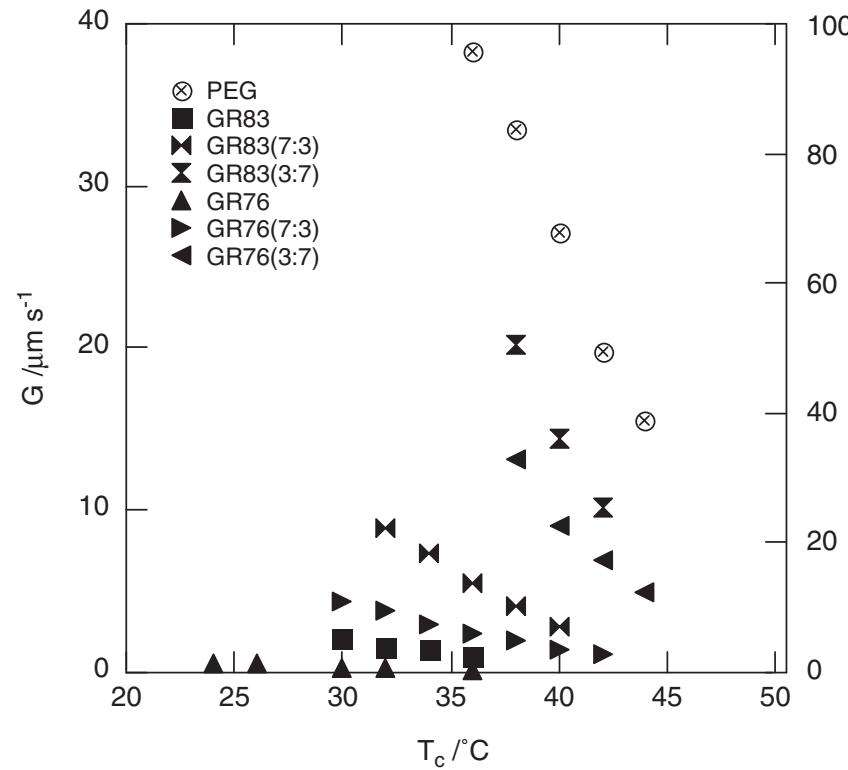

Figure 8 Growth rates of spherulites for graft copolymers and their blends with PEG. The ratio in parenthesis indicates the blend ratio of (graft copolymer):(PEG homopolymer) by wt. temperatures. Graft copolymers GR83 and GR76 were used in blend ratios of GR/PEG of 7:3 and 3:7 (wt). The plots of $\ln G$ against $\ln \phi_{2}$ at $1 / \Delta T=3.5 \times 10^{-2} \mathrm{~K}^{-1}$ are shown in Figure 6. A linear relationship was obtained including the point for the PEG homopolymer, in contrast to the results for the neat graft copolymers, suggesting that spherulite growth is governed by the homopolymer. As shown in Figure 9, extinction rings appear and the inside structure becomes less regular in spherulites as $T_{\mathrm{c}}$ increases; in addition, the homopolymer content is large. During the development of spherulites, crystalline lamellae are distorted by some interaction between the graft copolymer and homopolymer. It is not clear whether graft copolymers and homopolymers cocrystallize at the level of the crystalline lamellae, although both polymers cooperate to form a single spherulite. Further investigations, such as observations of long periods by small-angle X-ray scattering techniques, are needed to reveal cocrystallization.

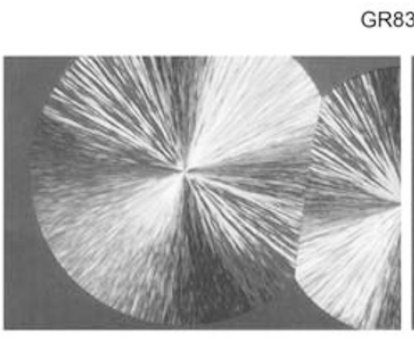

$7 / 3\left(38^{\circ} \mathrm{C}\right)$

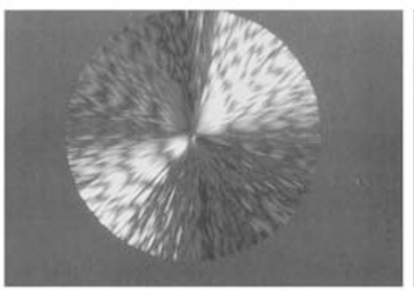

$3 / 7\left(40^{\circ} \mathrm{C}\right)$

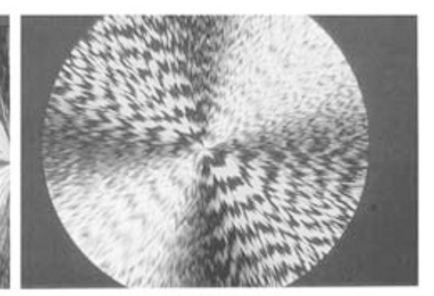

$7 / 3\left(40^{\circ} \mathrm{C}\right)$

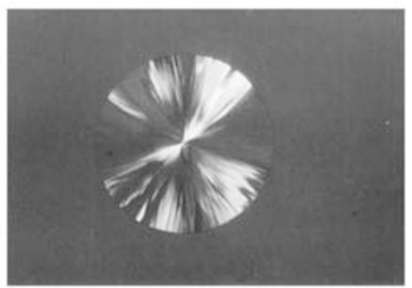

$3 / 7\left(44^{\circ} \mathrm{C}\right)$
GR76/PEG

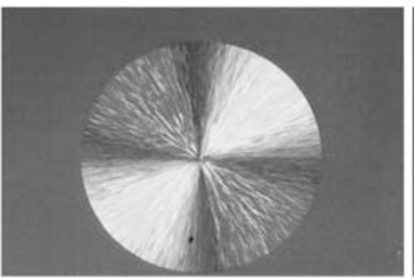

$7 / 3\left(40^{\circ} \mathrm{C}\right)$

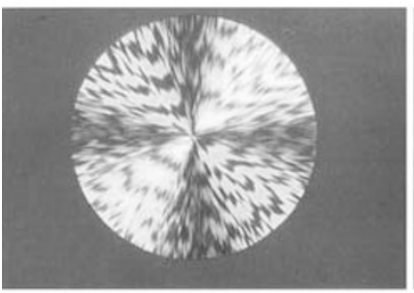

$3 / 7\left(40^{\circ} \mathrm{C}\right)$

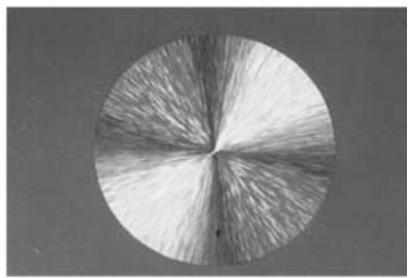

$7 / 3\left(42^{\circ} \mathrm{C}\right)$

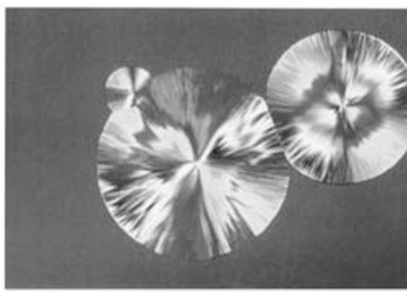

$3 / 7\left(44^{\circ} \mathrm{C}\right)$ $\overline{500 \mu \mathrm{m}}$

Figure 9 Morphology of spherulites for blends of graft copolymer with PEG homopolymer at the respective blend ratios and crystallization temperatures. 


\section{CONFLICT OF INTEREST}

The authors declare no conflict of interest

1 Mandelkern, L. Crystallization of Polymers, 2nd edn, Vol. 1, Ch. 4, 5 (Cambridge University Press, Cambridge, 2004).

2 Mandelkern, L. Crystallization of Polymers, 2nd edn, Vol. 2, Ch. 10, 11 (Cambridge University Press, Cambridge, 2004).

3 Nojima, S., Kato, K., Ono, M. \& Ashida, T. Time-resolved SAXS study of morphological change in a binary blend of poly( $\varepsilon$-caprolactone) and polystyrene oligomer. Macromolecules 25, 1922-1928 (1992).

4 Martuscelli, E., Pracella, M. \& Yue, W. P. Influence of composition and molecular mass on the morphology, crystallization and melting behaviour of poly(ethylene oxide)/poly(methyl methacrylate) blends. Polymer 25, 1097-1106 (1984).

5 Hamley, I. W. The Physics of Block Copolymer, Ch. 5 (Oxford University Press, Oxford, 1998).

6 Nojima, S., Kato, K., Yamamoto, S. \& Ashida, T. Crystallization of block copolymers. 1. Small-angle X-ray scattering study of an $\varepsilon$-caprolactone-butadiene diblock copolymer. Macromolecules 25, 2237-2242 (1992).

7 Shiomi, T., Takeshita, H., Kawaguchi, H., Nagai, M., Takenaka, K. \& Miya, M. Crystallization and structure formation of block copolymers containing a rubbery amorphous component. Macromolecules 35, 8056-8065 (2002).
8 Takeshita, H., Ishii, N., Araki, C. \& Shiomi, T. Crystallization and structure formation of block copolymers containing a glassy amorphous component. J. Polym. Sci. Part B 42, 4199-4206 (2004).

9 Shiomi, T., Tsukada, H., Takeshita, H., Takenaka, K. \& Tezuka, Y. Crystallization of semicrystalline block copolymers containing a glassy amorphous component. Polymer 42, 4997-5004 (2001).

10 Loo, Y. L., Register, R. A. \& Ryan, A. J. Polymer crystallization in 25-nm spheres. Phys. Rev. Lett. 84, 4120-4123 (2000).

11 Wang, T. T. \& Nishi, T. Spherulitic crystallization in compatible blends of poly(vinylidene fluoride) and poly(methyl methacrylate). Macromolecules 10, 421-425 (1977).

12 Pizzoli, M., Scandola, M. \& Ceccorulli, G. Crystallization kinetics and morphology of poly(3-hydroxybutyrate)/cellulose ester blends. Macromolecules 27, 4755-4761 (1994).

13 Risch, B. G., Wilkes, G. L. \& Warakomski, J. M. Crystallization kinetics and morphological features of star-branched nylon-6: effect of branch-point functionality. Polymer 34, 2330-2343 (1993).

14 Min, K. E., Chiou, J. S., Barlow, J. W. \& Paul, D. R. A completely miscible ternary blend: poly(methyl methacrylate)-poly(epichlorohydrin)-poly(ethylene oxide). Polymer 28, 1721-1728 (1987).

15 Ito, H., Russell, T. P. \& Wignall, G. D. Interactions in mixtures of poly(ethylene oxide) and poly(methyl methacrylate). Macromolecules 20, 2213-2220 (1987).

16 Turnbull, D. \& Fischer, J. C. Rate of nucleation in condensed systems. J. Chem. Phys. 17, 71-73 (1949)

17 Boon, J. \& Azcue, J. M. Crystallization kinetics of polymer-diluent mixtures. Influence of benzophenone on the spherulitic growth rate of isotactic polystyrene. J. Polym. Sci. Part A-2 6, 885-894 (1968). 